\title{
Metastatic Vulvar Carcinoma
}

National Cancer Institute

\section{Source}

National Cancer Institute. Metastatic Vulvar Carcinoma. NCI Thesaurus. Code C156066.

A carcinoma that arises from the vulva and has metastasized to another anatomic site. 